\title{
Is Surgery Justifiable in Residual locally advance breast cancer after neo-adjuvant systemic treatment?
}

\author{
Journal of Bioscience \& Biomedical Engineering
}

Research Article

Afsheen Javaid Khokher and Rufina Soomro*

Liaquat National Hospital \& Medical College, Karachi, Pakistan

\author{
Correspondence author
}

Rufina Soomro

Liaquat National Hospital \& Medical College

Karachi

Pakistan

E-mail : rufina.soomro@hotmail.com

Submitted : 30 Mar 2020 ; Published : 10 Apr 2020

\begin{abstract}
Background: Management of locally advanced disease is a challenge. In women with significant residual disease after neoadjuvant therapy when subjected to surgery wounds cannot be closed primarily and require myo-cutaneous flap, Latismus dorsi being the easiest one. The purpose of this study is to look at the recurrence rate, time to recurrence and is surgery needed in this group of patients.

Material and Methods: This is a hospital-based retrospective study conducted at Liaquat National Hospital and Medical College, Karachi. Pakistan. From 2006 to 2015, 15 patients with locally advanced breast cancer, who still had significant residual disease after adequate neo-adjuvant therapy that after Modified radical mastectomy wound could not be closed and latismus dorsi flap was used to close the defect. The age, histopathology report, margin of clearance, ER, $P R$, Her 2 status and ki67 was noted. These patients were followed up to look for any local or systemic recurrence and time to recurrence and local or site of any systemic recurrence was recorded.

Results: A total of 15 female patients with a mean age of $42.73 \pm 9.66$ years with a mean follow up of $33.93 \pm 26.78$ months were seen. In all patients, margins were histologically negative. Mean nodes removed and involved were $12.53 \pm 8.04$ and $5.46 \pm 7.15$ respectively. Meantime to recurrence was $16.00 \pm 14.92$ months. In our study, recurrence was observed in 11 (73.3\%) patients with 7(64\%) local and 4(36\%) systemic recurrence. All 5 triple-negative and 4 patients stage IV 4 had local recurrence. Patients with poor prognostic markers like higher residual nodal involvement, large tumor size, higher Ki 67, aggressive tumor biology (triple-negative and HER2 Positive tumors) had a high and early recurrence.

Conclusion: In patients with high residual tumor burden and aggressive biology has high chances of disease recurrence. Surgery in these patients should be offered to keep quality of life, disease biology and recurrence rate in mind.
\end{abstract}

\section{Keywords: Locally Advanced Breast Cancer, Neo-adjuvant Therapy, Surgery, Recurrence}

\section{Introduction}

Breast cancer is the second most common cancer and its incidence is persistently rising in the world is also the second most common cause of cancer-related death in women in the age group of 45 to 55 years [1]. Locally advanced Breast cancer is an aggressive class of breast cancer with poor prognosis and a high recurrence rate [2].

Locally advanced breast cancer is defined as a tumor with diameter greater than $5 \mathrm{~cm}$, frank skin and chest wall infiltration, matted axillary lymph node and inflammatory breast cancer [3]. Depending upon clinical definition among 1 out of 12 patients presents with locally advanced breast cancer [4]. 5 years survival

rate varies between 1 to $30 \%$ and overall median survival is 2 to 2.5 years [5].

It requires multimodality treatment, the sequence of its use has been variable. For various reasons upfront surgery has been done others prefer Neo-adjuvant therapy reason being it downstages the disease and improves surgical loco-regional control, and has the initial benefit of immediate effect on the occult micro-metastases $[6,7]$.

Key oncological management of locally advanced breast cancer includes neoadjuvant chemotherapy, appropriate use of surgery, 
including plastic and reconstructive techniques, radiotherapy, endocrine treatment and treatment with biological targeting therapy.

Breast cancer has a nonspecific response to treatment due to Heterogeneous disease nature. Depending upon the biological status of disease, some patients respond very well to first-line systemic treatment others even have chemotherapy resistance to $2^{\text {nd }}$ line or aggressive chemotherapy. Poor response to first-line neoadjuvant systemic treatment is a bad prognostic sign.

Despite standard treatment of care, LABC has a high recurrence rate both at the local and systemic sites. This Increase recurrence in locally advanced breast cancer is secondary to multiple factors i.e. nonpathological complete response has local and regional recurrence as high an incidence of $>50 \%{ }^{6}$, aggressive tumor biologies like HER 2 positive and triple-negative breast cancer TNBC, high Ki67 proliferative marker $(>14 \%)^{7}$ and residual nodal disease and locally advanced disease.

The role of surgery in locally advanced breast cancer with a poor clinical response after neoadjuvant chemotherapy is controversial. Some data suggest this is for local control of the burden of disease [8]. The aim of Surgery is to have a tumor-free pathological resection margin around cancer, as a positive margin has directly proportional relation to recurrence. The excision of bulky disease in breast cancer has difficulty in primary closure of the wound . Plastic surgery reconstructive techniques are used for wound closure, autologous flaps; particularly latissimus dorsi flap is the most common procedure [9].

Despite multimodality management, there is a higher incidence of early locoregional and systemic relapse leading to poor survival rate in patients with locally advanced breast cancer. This makes us think of the questionable benefit of aggressive surgery i.e. modified radical mastectomy with Latissimus dorsi flap for wound closure.

LD flap needs specialized training, need of plastic surgeon, donor site hospital morbidity, prolong hospital stay, which has the financial and psychological burden on patients along with aggressive use of resources. The purpose of this study to review management recommendations in patients with ulcerating breast cancer to improve quality of life, but also to avoid unnecessary surgical intervention in-patient who remained locally advanced even after neo-adjuvant treatment. There is scarcity of literature to compare the effect of surgery with no surgery. We wanted to look at the recurrence rate, time to recurrence and see if there is any association of recurrence with any risk factors. This may help us identifying who would benefit most from surgery in this group of patients or we use neo-adjuvant radiation and hormonal therapy or any other newer treatment options to manage these locally advanced breast cancer patients.

\section{Material \& Method}

The study was conducted in the General Surgery Department of Liaquat National Hospital \& Medical College, Karachi, Pakistan. It was a retrospective observational study. Data were collected retrospectively from hospital tumor registry from 2006 to 2015. A total of 15 patients with residual locally advanced infiltrating carcinoma of the breast were included. All patients had neoadjuvant chemotherapy with 1st line treatment of Anthracycline cyclophosphamide and taxanes. The patient who had not responded to this treatment was also given the trail of 2nd line chemotherapy i.e. Gemcitabine and Navalbine.

Despite of completion of principal neo-adjuvant chemotherapy Patients who have no or partial response and still need skin coverage for wound coverage after modified radical mastectomy after tumor-free margin resection were included, in cases of stage IV patients systemic disease controlled was confirmed by CT scan and bone scan after chemotherapy.

All 15 patients have histopathological complete removal of disease with negative resection margins and received adjuvant radiation therapy, hormonal therapy (according to their hormonal status) and targeted therapy to HER2 positive patients. Detail information of patient age, histopathology and biomarkers are collected from hospital electronic record. Patients who responded to neoadjuvant treatment and could undergo surgery with primary wound closure were excluded from the study.

Patients were followed on an outpatient basis on monthly for 3 months and then quarterly for clinical assessment of local or systemic recurrence and radiological assessment of contralateral breast. Local recurrence was confirmed by biopsy of local chest wall lesion along with metastatic workup (CT scan and bone scan) for systemic recurrence.

\section{Statistical Analysis}

Data were analyzed by using statistical package for social sciences (SPSS) version 25. Mean and standard deviation were computed for quantitative variable and frequency and percentage were calculated for qualitative variables. Stratification was done with regards to qualitative variables to see the effect of these modifiers on study groups by using Fisher's exact test. $\mathrm{p} \leq 0.05$ were considered as significant.

\section{Results}

Total 15 female patients with age 22 to 55 years were included in the study to observe the disease recurrence in locally advanced breast cancer patients, who had residual large tumor even after neo-adjuvant chemotherapy and required LD flap for wound coverage. The mean age of patients was $42.73 \pm 9.66$ years while mean follow up of patients was $33.93 \pm 26.78$ months.

Table 1: Descriptive statistics of Study Population

\begin{tabular}{|l|l|l|}
\hline & & $\mathrm{n}(\%)$ \\
\hline Age(years) & \\
\hline $\begin{array}{l}\text { Duration from } \\
\text { Surgery(Months) }\end{array}$ & & $42.73 \pm 9.66$ \\
\hline $\begin{array}{l}\text { Duration From } \\
\text { Registration(Months) }^{\circ}\end{array}$ & $22.26 \pm 23.18$ \\
\hline Nodes Removed $^{\circ}$ & $33.93 \pm 26.78$ \\
\hline Nodes Involved $^{\circ}$ & & $12.53 \pm 8.04$ \\
\hline \multirow{2}{*}{ T Stage $^{\circ}$} & Stage-III & $11(73.3)$ \\
\cline { 2 - 3 } & Stage-IV & $4(26.7)$ \\
\hline
\end{tabular}




\begin{tabular}{|l|l|l|}
\hline Nodal Status & Pno & $6(40)$ \\
\cline { 2 - 3 } & Pn1 & $3(20)$ \\
\cline { 2 - 3 } & Pn2 & $2(13.3)$ \\
\cline { 2 - 3 } & Pn3 & $4(26.7)$ \\
\hline
\end{tabular}

\begin{tabular}{|c|c|c|}
\hline \multirow[t]{4}{*}{ Histo Type } & IDC & $1(6.7)$ \\
\hline & $\begin{array}{l}\text { Invasive } \\
\text { carcinoma }\end{array}$ & $10(66.7)$ \\
\hline & $\begin{array}{l}\text { Invasive } \\
\text { Ductal }\end{array}$ & $3(20)$ \\
\hline & Metaplastic & $1(6.7)$ \\
\hline \multirow[t]{5}{*}{ Luminal } & $\begin{array}{l}\text { Luminal B, } \\
\text { Her } 2+\end{array}$ & $4(26.7)$ \\
\hline & Her2 positive & $4(26.7)$ \\
\hline & Luminal A & $1(6.7)$ \\
\hline & Luminal B & $1(6.7)$ \\
\hline & $\begin{array}{l}\text { Tripple } \\
\text { Negative }\end{array}$ & $5(33.3)$ \\
\hline \multirow[t]{3}{*}{ Ki67 Category } & Low ki67 & $1(6.7)$ \\
\hline & High Ki67 & $11(73.3)$ \\
\hline & NA & $3(20)$ \\
\hline \multirow[t]{2}{*}{ Recurrence } & Yes & $11(73.3)$ \\
\hline & No & $4(26.7)$ \\
\hline \multirow[t]{2}{*}{ Survival Status } & Alive & $12(80)$ \\
\hline & Expired & $3(20)$ \\
\hline
\end{tabular}

\begin{tabular}{|c|c|c|c|c|}
\hline \multirow{4}{*}{$\begin{array}{l}\text { Nodal } \\
\text { Status }\end{array}$} & Pn0 & $3(27.3)$ & $3(75)$ & \multirow[t]{4}{*}{0.300} \\
\hline & Pn1 & $2(18.2)$ & $1(25)$ & \\
\hline & Pn2 & $2(18.2)$ & $0(0)$ & \\
\hline & Pn3 & $4(36.4)$ & $0(0)$ & \\
\hline \multirow[t]{3}{*}{$\begin{array}{l}\text { Histo } \\
\text { Type }\end{array}$} & \begin{tabular}{|l|}
$\begin{array}{l}\text { Invasive } \\
\text { ductal }\end{array}$ \\
\end{tabular} & $8(72.7)$ & $2(50)$ & \multirow[t]{3}{*}{0.582} \\
\hline & & $2(18.2)$ & $1(25)$ & \\
\hline & Metaplastic & $1(9.1)$ & $0(0)$ & \\
\hline \multirow[t]{5}{*}{ Luminal } & $\beta$-Her & $2(18.2$ & & \multirow[t]{5}{*}{0.212} \\
\hline & Her2 & $3(27.3)$ & $2(50)$ & \\
\hline & Luminal A & $0(0)$ & $1(25)$ & \\
\hline & Luminal B & $1(9.1)$ & $0(0)$ & \\
\hline & \begin{tabular}{|l|} 
Tripple \\
Negative \\
\end{tabular} & $5(45.5)$ & $0(0)$ & \\
\hline \multirow{3}{*}{$\begin{array}{l}\text { Ki67 } \\
\text { Category }\end{array}$} & Low ki67 & $0(0)$ & $1(25)$ & \multirow[t]{3}{*}{0.396} \\
\hline & High Ki67 & $8(72.7)$ & $3(75)$ & \\
\hline & NA & $3(27.3)$ & $0(0)$ & \\
\hline
\end{tabular}

Fisher exact test was applied.

$\mathrm{P}$-value $\leq 0.05$ considered as significant.

In our study recurrence was observed in $11(73.3 \%)$ patients with 7(64\%) local and 4(36\%) systemic recurrence. All 5 triple-negative and 4 patients stage IV 4 had a local recurrence (100\% recurrence). Though overall in our study due to small sample size results show an insignificant association of recurrence and survival status with age, T-stage, Nodal status, histology type, luminal type and ki67 but on an individual basis, it was observed that patients with a poor prognostic marker like higher residual nodal involvement, large tumor size, higher Ki 67, aggressive tumor biology (triple-negative and HER2 Positive tumors) had high and early recurrence, so these parameters should be checked before any major surgical intervention to avoid unnecessary surgery.

Table 3: Association of Survival status with population characteristics stage-IV. On molecular basis 1 (6.7\%) luminal A, $1(6.7 \%)$ luminal B, 4(26.7\%) Hormone receptor and Her2 positive, and 4(26.7\%) HER 2 Positive and ER and PR negative and $5(33.3 \%$ were triple-negative. $14(93 \%$ of patients were present in the High Ki67 (>14\%) group.

Table 2: Association of recurrence with population characteristics

\begin{tabular}{|l|l|l|l|l|}
\hline \multirow{2}{*}{$\begin{array}{l}\text { Age } \\
\text { Group }\end{array}$} & $\leq 40$ years & $5(45.5)$ & $1(25)$ & \multirow{2}{*}{ Pecurrence $\mathrm{n}(\%)$} \\
\cline { 3 - 4 } & $>40$ years & $6(54.5)$ & $3(75)$ & \multirow{2}{*}{0.604} \\
\hline \multirow{2}{*}{ T Stage } & Stage-III & $7(63.6)$ & $4(100)$ & 0.516 \\
\cline { 2 - 4 } & Stage-IV & $4(36.4)$ & $0(0)$ & \\
\cline { 3 - 4 } & & & & \\
\hline
\end{tabular}

\begin{tabular}{|l|l|l|l|l|}
\hline \multirow{2}{*}{ Age Group } & & \multicolumn{2}{|l|}{$\mathrm{n}(\%)$} & \multirow{2}{*}{ P-Value } \\
\cline { 3 - 4 } & & Alive & Expired & \\
\cline { 2 - 4 } & $>40$ years & $5(41.7)$ & $1(33.3)$ & \multirow{2}{*}{1.000} \\
\hline \multirow{3}{*}{ T Stage } & Stage-III & $7(58.3)$ & $2(66.7)$ & \\
\cline { 2 - 4 } & Stage-IV & $3(25)$ & $2(66.7)$ & 1.000 \\
\hline \multirow{3}{*}{$\begin{array}{l}\text { Nodal } \\
\text { Status }\end{array}$} & Pn0 & $6(50)$ & $0(0)$ & \multirow{2}{*}{0.185} \\
\cline { 2 - 4 } & Pn1 & $2(16.7)$ & $1(33.3)$ & \\
\cline { 2 - 4 } & Pn2 & $2(16.7)$ & $0(0)$ & \\
\cline { 2 - 4 } & Pn3 & $2(16.7)$ & $2(66.7)$ & \\
\hline
\end{tabular}




\begin{tabular}{|l|l|l|l|l|}
\hline Histo Type & IDC & $1(8.3)$ & $0(0)$ & \multirow{2}{*}{0.440} \\
\cline { 2 - 4 } & Invasive & $8(66.7)$ & $2(66.7)$ & \\
\cline { 2 - 4 } & $\begin{array}{l}\text { Invasive } \\
\text { Ductal }\end{array}$ & $3(25)$ & $0(0)$ & \\
\cline { 2 - 4 } & Metaplastic & $0(0)$ & $1(33.3)$ & \\
\hline \multirow{5}{*}{ Luminal } & $\beta-$ Her & $3(25)$ & $1(33.3)$ & \multirow{4}{*}{1.000} \\
\cline { 2 - 4 } & Her2 & $3(25)$ & $1(33.3)$ & \\
\cline { 2 - 4 } & Luminal A & $1(8.3)$ & $0(0)$ & \multirow{4}{*}{1.000} \\
\cline { 2 - 4 } & Luminal B & $1(8.3)$ & $0(0)$ & \\
\hline \multirow{3}{*}{$\begin{array}{l}\text { Kateg } \\
\text { Category }\end{array}$} & Low ki67 & $1(8.3)$ & $0(0)$ & \\
\cline { 2 - 4 } & High Ki67 & $9(75)$ & $2(66.7)$ & \\
\cline { 2 - 4 } & NA & $2(16.7)$ & $1(33.3)$ & \\
\hline
\end{tabular}

Figure 1: Frequency of disease recurrence

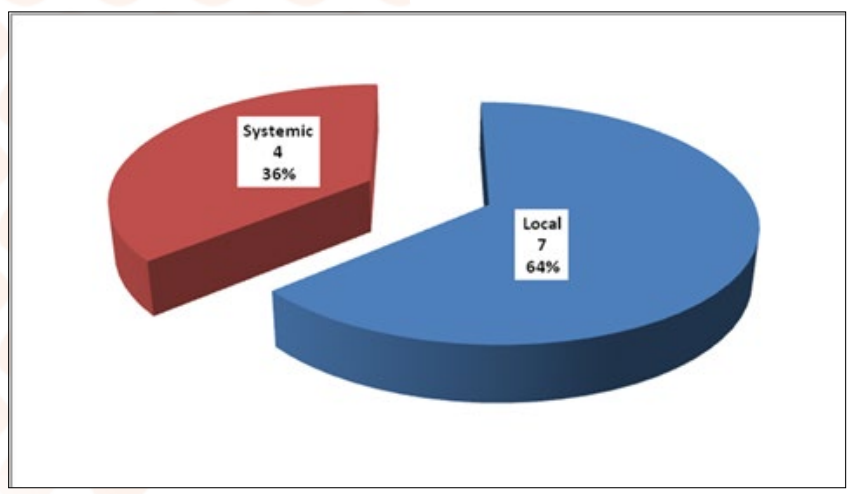

Figure 2: Association of Recurrence status with Population characteristics

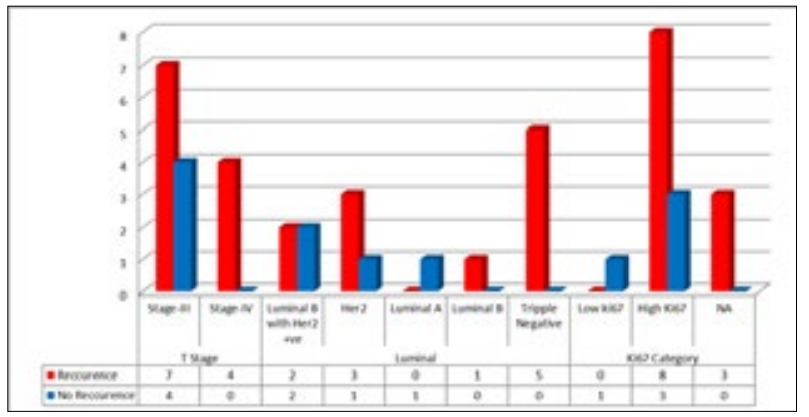

Figure 3: Association of Survival status with Population characteristics

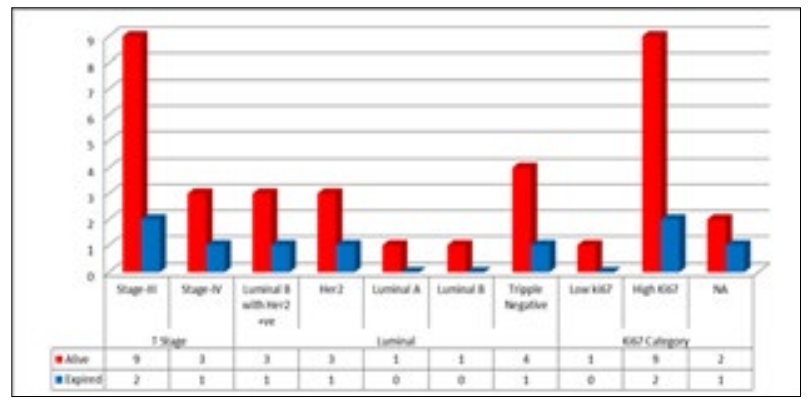

Discussion

Locally advanced breast cancer is a violent disease to begin.

The cause of it is the delayed presentation as well as the nature

of the disease with bad tumor biology. Multi-disciplinary management is necessary for the management of locally advanced breast cancer. It has no standard therapy protocol, as this patient group is very heterogeneous. The rate of local recurrence ranges from $12 \%$ to $30 \%$, depending on the length of follow-up [10]. In this intellect, the ideal therapy should be tailored and individualized considering the patient characteristics, i.e. tumor size, ER, PR, human epidermal growth factor receptor-2 (HER2), local extension, and lymph nodes invasion status [11].

Neo-adjuvant chemotherapy is the standard of care for patients followed by surgery and adjuvant radiotherapy. All these measures are executed to control the locoregional disease and to eradicate distant metastasis. Patients with more advanced nodal disease and a high Ki67 index had a higher risk of locoregional relapse. Similarly, aggressive subtypes triplenegative breast cancers and Her 2 positive has a poor prognosis with high local recurrence and has shorter overall survival than those with luminal subtypes [12].

The role of surgery in locally advanced breast cancer is to remove local disease either by mastectomy with primary closure (if possible) or with plastic reconstruction LD flap to provide wound closure. In developing countries, this procedure is also used as first-line therapy due to the unavailability of resources or financial constraints to relieve patient bothersome symptoms and disease burden. But this time being management has no effect on disease prognosis recurrence or survival [13$15]$.

In our study, we observed all patients who followed standard treatment care, neo-adjuvant chemotherapy, surgery with clear resection margin and adjuvant radiotherapy and hormonal and targeted treatment according to biomarker status. Despite all preventive measures we observed $64 \%$ recurrence within the first 2 years. This high recurrence shows the failure of local surgical treatment to control local recurrence. So putting the patient under the knife has shown a very low beneficial effect. This provokes the role of surgery in these patients unpredictable.

In nutshell, $\mathrm{LABC}$ is considered a worse type of $\mathrm{BC}$, which is accountable for fatal prognosis, resulting in low survival. LABC has the tendency to spread very fast and initiate inflammatory injuries in case of inflammatory breast cancer. Moreover, $\mathrm{LABC}$ is associated with challenging treatment, since LABC frequently present chemotherapy resistance. To solve this impediment, new studies are being purposed to discover alternate remedies to recover treatment responsiveness.

Our study has limitations because of its retrospective design with a very small sample size from which to draw meaningful conclusions is difficult. But we can identify high-risk patients and think other modalities like the role of neoadjuvant radiotherapy and hormonal therapy in $\mathrm{LABC}$ and much more research work is needed to check the need for surgery. 


\section{Conclusion}

After neo-adjuvant therapy, patients with high residual tumor burden and aggressive biology has high chances of disease recurrence even in patient's histologically tumor-free margins. Extensive Surgery requiring myo-cutaneous flaps in these patients should be offered to keep quality of life, disease biology and recurrence rate in mind.

\section{References}

1. Jemal A, Siegel R, Ward E, Hao Y, Xu J, et al. (2009) Cancer statistics, 2009. CA Cancer J Clin 59: 225-249.

2. Newman LA (2009) Epidemiology of locally advanced breast cancer. Semin Radiat Oncol 19: 195-203.

3. Tryfonidis K, Senkus E, Cardoso MJ, Cardoso F (2015) Management of locally advanced breast cancerperspectives and future directions. Nat Rev Clin Oncol 12: $147-162$.

4. Newman LA (2009) Epidemiology of locally advanced breast cancer. Semin Radiat Oncol 19: 195-203.

5. Giordano SH (2003) Update on locally advanced breast cancer. Oncologist 8: 521-530.

6. Qureshi AU, Cheema MA, Sidra Shoaib Qureshi, Azhar Bashir (2014) Latissimus dorsi flap (LDF) for the closure of large chest defects after excision of locally advanced fungating carcinoma breast as a treatment option- a multicenter experience 2014: 1845.

7. Scholl SM, Fourquet A, Asselain B, Pierga JY, Vilcoq JR, et al. (1994) Neoadjuvant versus adjuvant chemotherapy in premenopausal patients with tumors considered too large for breast-conserving surgery: preliminary results of a randomized trial. S6. Eur J Cancer 30A: 645-652. Ann Oncol 30A: 645.

8. Nielsen DL (2004) Mechanisms and functional aspects of multidrug resistance in Ehrlich ascites tumor cells. Dan Med Bull 51: 393-414.

9. Brackstone M, Fletcher GG, Dayes IS, Madarnas Y, SenGupta SK, et al. (2015) Locoregional therapy of locally advanced breast cancer: a clinical practice guideline. Curr Oncol 22: S54-66.

10. Weledji, Elroy P (2017) International Journal of Surgery Oncology (2017) 2:e0"Primary surgical treatment of locally advanced breast cancer with heavy nodal involvement: a case report. IJS Oncology 2: e08.

11. Liang Huang, Sheng Chen, Wentao T Yang. Zhiming Shao (2017) Risk factors of locoregional relapse in locally advanced breast cancer treated with neoadjuvant chemotherapy following mastectomy and radiotherapy. Oncotarget 8: 39703-39710.

12. Hébert-Croteau N, Brisson J, Latreille J, Rivard M, Abdelaziz N, et al. (2004) Compliance with Consensus Recommendations for Systemic Therapy is Associated with Improved Survival of Women with Node-Negative Breast Cancer. J Clin Oncol 22: 3685-3693.

13. C Denkert, S Loibl, BM Muller, H Eidtmann, WD Schmitt, et al. (2013) Ki67 levels as predictive and prognostic parameters in pre-therapeutic breast cancer core biopsies: a translational investigation in the neoadjuvant GeparTrio trial. Annals of Oncology 24: 2786-2793.

14. Onyinye D Balogun, Silvia C Formenti (2015) Locally advanced breast cancer - strategies for developing nations. Front Oncol 5: 89.

15. Haffty BG, McCall LM, Ballman KV, McLaughlin S, Jagsi R, et al. (2016) Patterns of Local-Regional Management Following Neoadjuvant Chemotherapy in Breast Cancer: Results From ACOSOG Z1071 (Alliance). Int J Radiat Oncol Biol Phys 94: 493-502.
Copyright: (C2020 Rufina Soomro. This is an open-access article distributed under the terms of the Creative Commons Attribution License, which permits unrestricted use, distribution, and reproduction in any medium, provided the original author and source are credited. 